\title{
Existence (or, Our Patient with Superpowers)
}

\author{
Andrew J. McLean ${ }^{1}$
}

Received: 19 April 2017 / Accepted: 30 May 2017 / Published online: 21 July 2017

(C) Academic Psychiatry 2017

Artist's Statement

Empathy refers to the capacity to understand another's experience (thoughts/feelings/attitude) from their perspective. As providers, we often forget what that experience is like. This poem about a clinic patient is a gentle reminder.
Existence (or, Our Patient with Superpowers)

"Good morning, Iris," I said.

She replied, "How do you know my name?"

Her unstated question actually was,

"WHY do you know my name?"

Not from a stance of vigilance,

But rather, a lack of belief

that there would be acknowledgement

of her value, of her being, of her

presence on this earth.

An early life of trauma and thereafter, serious mental illness with frequent visits over decades to our clinic.

Her gray clothing allowing her

to blend in to the waiting room furniture;

Eyes downcast, features non-clinically catatonic,

Undiscoverable.

Magically able to rematerialize

at the designated time to see

her case manager, her peers or

my psychiatrist colleague.

"Of course I know your name," I grinned.

She smiled back.

Andrew J. McLean

andrew.mclean@med.und.edu

1 UND School of Medicine and Health Sciences, Fargo, ND, USA 